\title{
Imagining the Essay as Digital Assemblage: Collaborative Student Experiments with Writing in Scalar
}

\author{
Dwayne Dixon, Duke University
}

January 1, 2017

\begin{abstract}
This essay describes a digital, collaboratively designed and interconnected series of essays that were the final project for a first-year class in media and anthropology. These essays were composed using a digital, publically accessible, scholarly publishing platform that allows students to experiment architecturally with arguing related ideas through non-linear text. The result is an intricate, flexible pathway of pages. The assignment is informed by, and attempts to experimentally enact, Fèlix Guattari's concept of the assemblage, emphasizing movement and process of argument and evidence over static, reified trajectories of traditional essay composition. By examining the periphery of their own ideas, students encounter the interpretations of their classmates and discover alternate readings of key themes, which they can then fold into their own writing networks, ultimately creating a textual flow which challenges the singularity of the author and the boundaries of disciplinary thinking.
\end{abstract}

A collaborative, digitally interconnected essay project was the final assignment for a class of seventeen first-year, first-semester students, enrolled in a writing-intensive seminar on media and anthropology. Together, we studied the history of media, the role of technology in society, and technology's mutable cultural meanings. We began the semester by exploring theories of media in order to provide us with the connective and analytic tools necessary to make sense of the wide scope of our readings. Using Karl Marx, Felix Guattari, Sherry Turkle, Nancy Baym, Bill Nichols, and Raymond Williams, among others, we attempted to understand the way the meanings and modes of media have affected social life and identity across different times and spaces, from cinema in colonial Nigeria to torture photographs made in Abu Ghraib to the radically different virtual worlds of Second Life and U.S. drone pilots. 
Even though this course specifically focuses on media and anthropology, it was created for students who are still exploring their majors, have a range of writing abilities, and come from various cultural and linguistic backgrounds. Since this is a first-year course, students have a range of experiences and understandings of how the classroom and "education" operate, both culturally and technically. These diverse students require a flexible approach to teaching and assessment that accounts for their needs and calls on their strengths. Opportunities for creative and challenging group work are crucial to engaging the learners beyond their anxious attention on traditional markers of (graded) performance. To divert the first-year nervousness over mastering the texts (at the expense of ideas) and orient their energy on developing writing habits, I chose to use an alternative form to the traditional essay, one where the technical aspects of formal transmission could shape the relations between ideas and allow for "writing" through the medium itself. A usual writing assignment in an anthropology course on media would require students to create a linear text, building an argument from ethnographic texts and theory to challenge the reader with new insights. In designing a non-linear text, students confronted how ideas and arguments are created through the structure of language and how the mediated form of these ideas and arguments shape their meaning.

As the class attempted to unsettle the relations between communications technologies and culture, it was equally important to also challenge the form of the arguments about these very relations. I chose to use Scalar, an online digital publishing platform designed specifically for humanities and social science scholarship. Scalar offered the ability for students to present information and ideas in discrete pages, embed video and audio, and incorporate layers of analysis and commentary in the form of pop-up footnotes. Not only would authors be able to craft a larger text from molecular visual and textual components, but they could also structure the reader's journey through intersections of concepts, through forking lines of inquiry, and along connected pathways where arguments could coalesce from the way pages could be multiply linked and tagged. In short, this platform invited non-linear approaches to complex questions and textual methods.

This assignment, grounded in Scalar, opens up a field of play and collaboration with the process of thinking and creating rather than emphasizing advanced compositional, language, and analytic skills. Students' writing and connections progress visibly over time as themes and ideas expand across the threads of different authors. Because the project is staged in such a visible and traceable way, it allows many opportunities for the instructor and fellow students to challenge and counsel. Students responded well to this staged approach to their writing and project creation, since it alleviated anxiety about "getting it wrong" while fostering communal knowledge sharing about Scalar itself and the ideas they were working on. Significantly, the excitement around figuring out the conceptual, intellectual, and spatial content of the various projects also generated a warm proximity between the students and myself, as I was able to visit different groups during their sessions outside of class and respond individually to students' queries. A sense of shared investment and care in the project exceeded any quantifiable metric of success but was confirmed through the feedback students provided at the end of the semester. 
Scalar's architecture is premised on variable relationships and paths. Students can approach the platform as a zone to experiment with the relationship between content and form. Specifically, the writing process is one of modular development as arguments are crafted from smaller, concise pieces of writing focused on key texts, examples, concepts, and theories. In this final assignment, students contend with a wide sweep of media histories and ideas encountered over the course of the semester. However, the very modularity of the project, combined with the opportunity to build on previous short essays, alleviates the sense of being overwhelmed by material that students often express when trying to formulate a traditional paper of ten to fifteen pages.

Scalar projects are typically comprised of a basic unit-a "page"-that can be multiply connected through keyword tags, hyperlinks, and more complex linkages unique to the Scalar platform. These connections operate within the work of a single author and extend across group projects. This connectable modularity provides a manageable structure for students to explore distinct but related concepts. It also demonstrates how writing operates at different levels insofar as the reader travels in and across texts at different speeds, with different intentions or destinations in mind, and with various conceptual horizons becoming visible in the encounter.

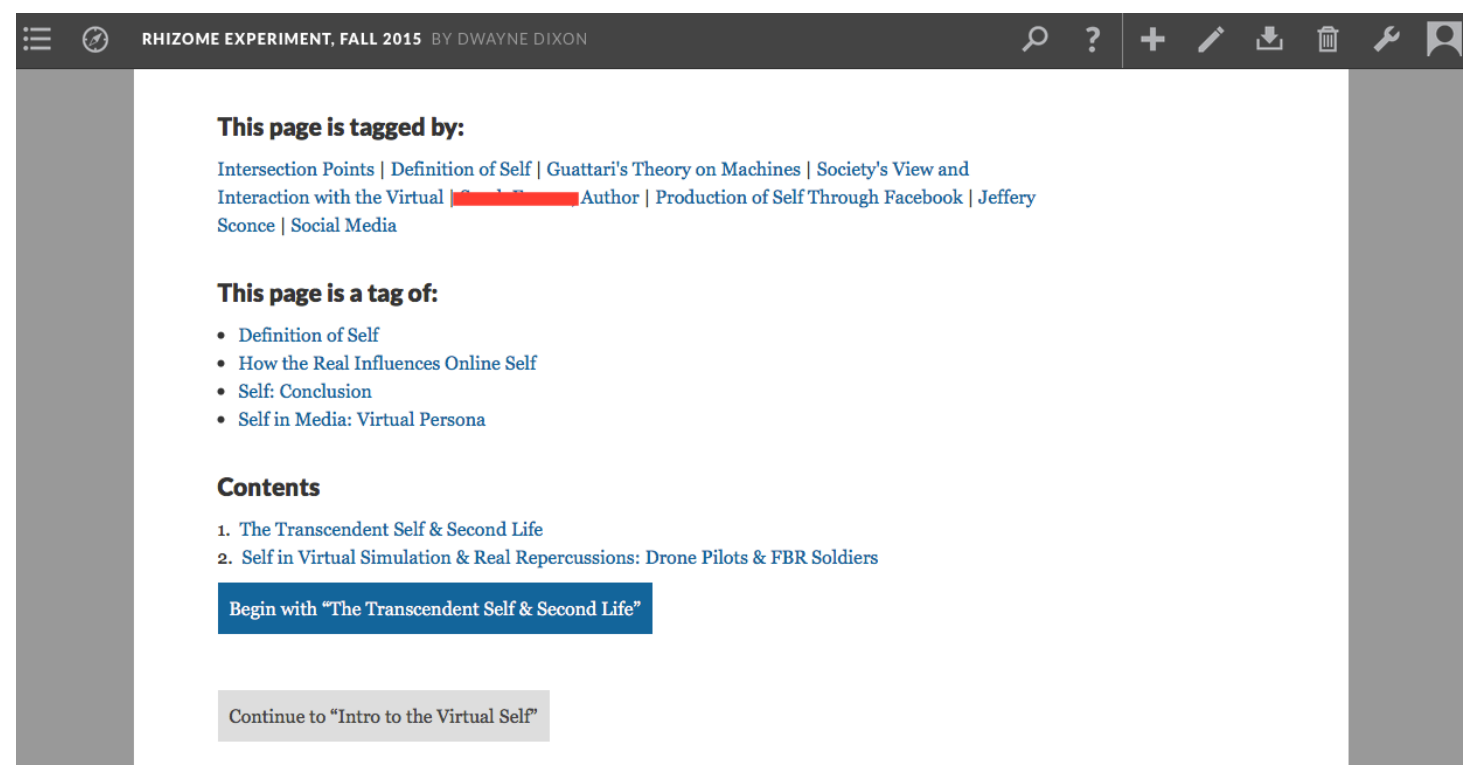

By building "paths" of sequential pages and tagging these pages with collectively agreed-to terms, the author demonstrates in the indexical and navigation information at the bottom of her page how a reader might proceed depending on their interests or desire to circulate in new directions from previously encountered material.

Through this thematic and theoretical organizational process of scaled, modular construction, the students can begin to link their writing together organically. Once small groups of students tightly connected their various pages around broad themes, they began to send out tendrils to other thematic nodes, pulling their collective work together into an expansive and collaboratively tangled assemblage of knowledge. I use tangled 
intentionally here because there is no way to extract a dominant hierarchy or overriding linear trajectory from what the students compose. Arguments are taken up, lines of thinking are pursued, and then they morph, or dissipate, or fold into an adjacent idea, only to re-emerge again.

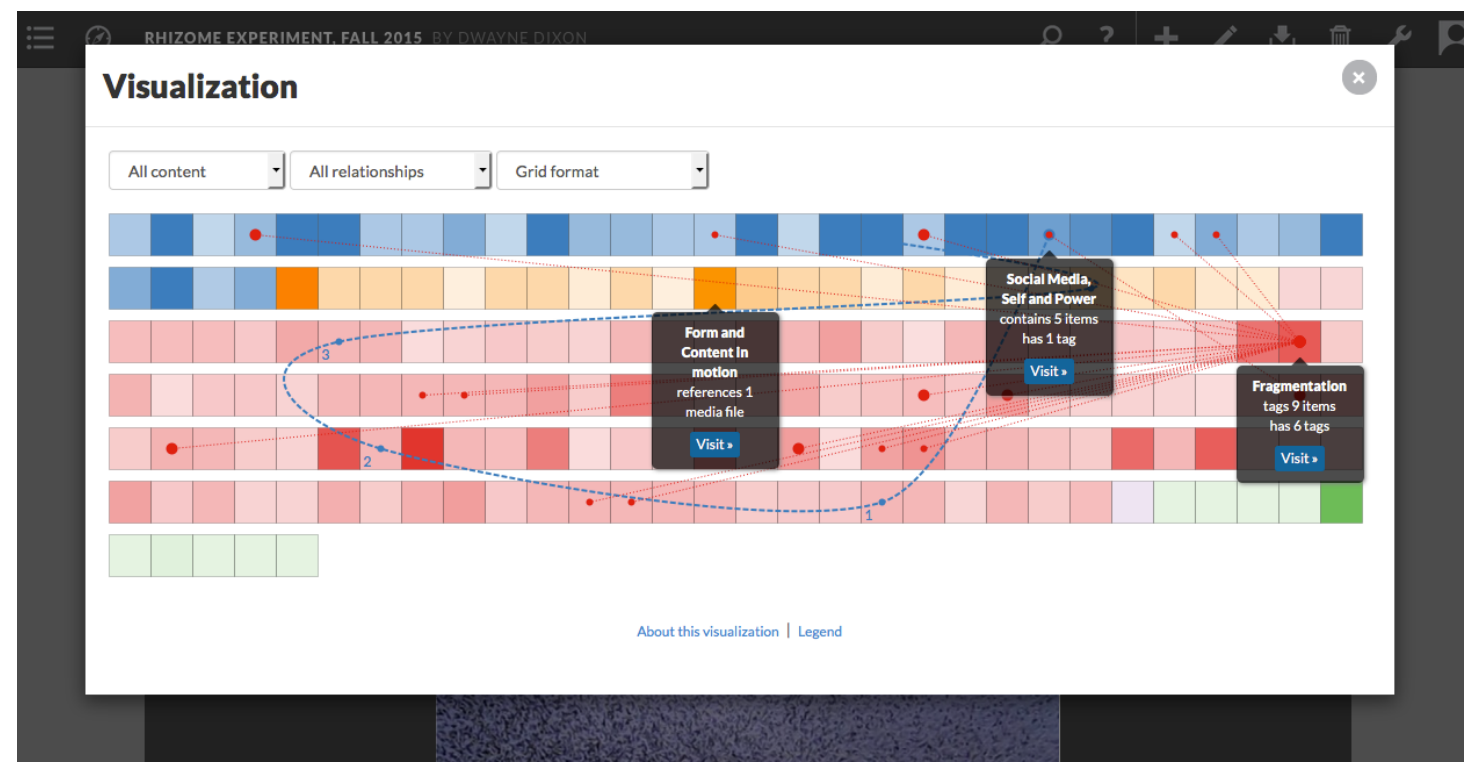

This image shows a pop-up visualization map of the project with layers of pages, paths, tags, and media displayed in a straightforward grid. As a reader scrolls and clicks on various blocks, relationships between them are revealed, allowing for alternate modes of navigation supplementary to the in-text flow created by the authors.

The lack of linearity combined with the expansive, collectively built structure was confusing and distressing to some of the students when I introduced the assignment. The form of the assignment did not align with the habitual expectations of how students are supposed to display their knowledge. There was no given, singular argument they had to put forward. No self-evident hierarchy was available. Moreover, rather than having the semester's previous writing molder away in the digital vault, I asked them to incorporate previously revised pieces they wrote for the class, in whole or in part, to build their current writing. The project was proposed as an opportunity to think actively with their classmates and remix/resurrect their previous writing.

Together they could enact, formally, living knowledge in a collectively produced and critiqued digital landscape. In small, self-selected groups they would grapple with the problem of building coherent ideas into related sets or strata of knowledge while discovering shared facets or connections and using the platform's technical features to elaborate those connections and make them visible as pathways (or rabbit holes!) for readers. You can become one of these readers by visiting the site and perusing it yourself: http://scalar.usc.edu/works/rhizome-experiment-fall-2015/index

We read Fèlix Guattari's discussion of the assemblage from his last book, Chaosmosis. Guattari returns, here, to the concept of the assemblage as the way heterogeneous 
components relate in the formation of subjectivities (1995). The dense theoretical language resists easy reading, but the students find themselves returning to some of his key terms, particularly the "machine" as a form of movement and process in opposition to structure-a useful interruption in the more conventional and material understanding of the machine within histories of media. But it is the assemblage that is most valuable for the class because it articulates how ideas, parts, components, can be joined for a purpose but then exchanged into other arrangements with new functions appearing. The assemblage asserts the unanticipated possibility curled within every object, ritual, and social formation, expressed through new contacts and relations. The exchangeable, emergent, and mobile characteristics of the assemblage encourages students to tinker with the staid functionality of essay forms they learned in high school and to employ revision and remixing as liberating exercises in the discovery of ideas on the periphery of a parched thesis.

The students created an elaborate, complex, and intellectually rich assemblage as they drew on a diversity of ideas, experiences, and theories. While "media" may not seem to contain or define the entirety of the project, it provided the central ballast and reappeared surprisingly within the dense relationships the students mapped. In its wondrous asymmetry, the project animates the distinction Deleuze and Guattari make between a map and a tracing: "The map is open and connectable in all of its dimensions; it is detachable, reversible, susceptible to constant modification... A map has multiple entryways, as opposed to the tracing, which always comes back "to the same'" (1987, p. $12)$.

So too this project offers multiple entryways. It is never closed, nor finished. Through this assemblage the students encountered their own intimate differences between each other, but also discovered how those differences can be productively woven together to build a fluid space of knowledge that far outstrips each individual capacity. The form invites their differences and then mutates the fixed position of each difference into something else through proximity and connection.

Tianlin Duan, one of the student architects of this project, writes eloquently on Scalar about its scope and possible effects:

Viewing everything as being connected blurs and tears down the boundaries. Or, did we "invent" those binaries in the first place? Are there real boundaries between human and machine, real and simulated, social and technology? While technology is becoming an increasingly indispensable part of our life, we're also endowing it with more humanness through vital and intellectual input; while simulation is indeed an imitation of the real, it is also transforming the present real and designing the future real; while social forces influence how we use and interpret technology, technology also re-defines the social interactions and connections that define how we make sense of ourselves. Perhaps the binaries, the supposed opposing standing of these are based and only based on our ideology. Instead of boundaries, there is the ever-existing process of becoming. 
What Duan describes is explicitly about the intellectual terrain of the project and how objects of analysis are given shape through boundaries of formal definition, shapes that shift and give way to other forms. The complex tensions she lays out persist throughout the entire project, sometimes in exquisite detail, other times seen only obliquely until arriving upon an idea again from another entryway constructed by a different student. The textual topography is uneven: some students elected to submit no revised work and wrote entirely new text, while others devoted many hours to honing and reshaping their earlier, more classically organized essays. Individual projects still suffered familiar problems: some examples deployed by students were bereft of careful analysis while in other authors let theories sometimes drift away from the ethnographic ground we had meticulously studied.

From the outset, I am very clear with the students about the anarchist and rhizomatic form of the project, and we spend a portion of a preparatory class talking about how the group benefits as a whole when individuals in their nodes produce work that is useful and how intellectual work, like labor generally, depends on collective resources and sharing. Of course, not every student succeeds in integrating their writing with the dynamic writing space of Scalar, but they reap the benefits of connecting to others' knowledge and insights. Using Scalar allows me to quickly assess student effort and struggles, as time-stamped, archived versions of each page are available for viewing by administrators of the project. This cumulative measure of progress provides me a metric in considering the student's broader efforts and interactions: did they avail themselves of office meetings? Did they email questions? Did they ask me to review an outline or talk to me after class about key parts of previous papers they hoped to revise and include? Did they have technical questions?

The project does not guarantee success in a uniform way. Students who do "poorly" are those who have generally shown a low interest in the material and simply want to insert conventional text into the Scalar pages-a clunky solution that demonstrates limited engagement. That is the student's choice, ultimately, and one they make even as they are able to see the progress and innovations of their peers. I visit each of the node clusters in their meetings and have them send me copies of their group notes, photos of their maps/schematics, or whatever sort of guide they are collectively working from. I intentionally use the project as a way to interact with the students outside of class and think with them together in their small groups when students are perhaps less inhibited because they are task-focused. By being involved throughout their process, I am able to ensure good quality work and collaboration as I can talk through problems quickly or push on ideas. This older, time-intensive, analog model of teaching takes on new life when paired with Scalar's ability to allow new questions about writing and reading.

However messy and incomplete, the project required the students to critique their own formal approaches and reconcile their approaches with those of others. At the same time, they had to explore aspects of their own work they ignored or overlooked as others incorporated their ideas into unexpected formations and thus often brought attention to secondary or peripheral arguments. They learned that together they possessed greater 
knowledge than any single individual and that their strengths were amplified when working creatively through formal mechanisms intended to draw their ideas into concert without overwriting their intellectual autonomy. It is the assemblage, with its assertion of process over singular function, that prevailed.

In our concluding class, we watched a beautiful video of a starling murmuration that occurred somewhere in Scotland. We took this elegant example from nature as a guide. Eschewing perfection, the students struggled to compose something that is always shifting, always attempting to find other possible shapes from which new possibilities and new ideas might become visible. The students' work asks us to rethink what we imagine as writing and how collective intellectual production happens, especially around the intense events, ideas, and concepts that permeate our everyday lives, from social media to the prison system to drone strikes to labor and love in the virtual world.

\section{Assignment-Network(ed) Knowledge: Synthesis and Expansion}

See the Supplementary Files for this article at thepromptjournal.com for a PDF facsimile of the original formatting of this assignment.

CulAnth 20S-03 Media and Anthropology Writing Intensive, First Year Seminar Fall, 2014

\section{Synthesis and Expansion}

Overview: Final projects always demand more than they can ever be. The terminus of our encounter as a class through the education machine is arbitrary - a mechanism for regulation and statistical production, namely, a grade. It attempts to impose an order on knowledge we already know is chaotic and unruly, exceeding the capacity of any grade to capture it.

With that said, I propose the "final" we arrive at should become a moment/event/space for us to discover new paths, new networks - this is how we survive and grow. One basic and critical way to do this is for us to re-imagine the form through which we express our knowledge, complete with doubts and confusions.

To help us with question of form this project will be electronically published using the nonlinear design possibilities of Scalar. This will require you to think about how writing itself works as a form of media. Read more about Scalar here: http://scalar.usc.edu/scalar/

All of you have struggled intensively with complex ideas this semester. The goal has never been mastery of knowledge (often an illusion), but to create new possibilities for 
you to think and act upon, both in yourself as a fleshy, social being and in the worlds you inhabit and build with others.

For this last project, I want you to continue to develop lines of thought you've been tracing in your previous 2 conventionally structured essays. Rather than confining these essays to the crypt of your hard-drive, I want you to animate them in new ways - allow them to change shape, to become heterogeneous as they make contact with sister ideas manifested in the work of your classmates.

Your task is to summarize, organize and integrate your knowledge and that of your classmates/fellow thinkers while expanding on these ideas through new examples and more complex analyses.

Each of you will have total autonomy over your own path within the class Scalar project. Within that, I imagine you might devote a page or several to some foundational concepts regarding the machine, media, the social/tech interface, society and change, time/space, labor, or haunting. You may also explore more deeply some sites/examples in which these concepts are evident, such as Second Life. You may decide to research a "new" theorist (Baudrillard! Deleuze!) or dig more deeply into a familiar one (Marx, that rascal! Or Guattari!). Maybe you will do a combination of these things.

After you've decided on a thematic focus for your project, we will collectively organize the entire class into 4 or 5 nodes, each with a shared thematic focus. This means groups of 3 to 4 students will work together.

Because the project is NOT linear, your ideas can be more mobile, more provocative, and more generous in their reach. This does not mean they are not focused. Make this project about one or several related topics (surveillance, the virtual, war-making and simulation, online romance, changing parameters of friendship among adolescents under the intensified time/space of Facebook, bullying, virtual currencies, the role of social media in the uprisings in Tunisia and Egypt, etc). This will allow your work to cohere and also give you a direction when you go off rambling into the internet woods to see what you can find in terms of stories, videos, etc. However, I encourage you to be experimental, to try out new things, to go into new spaces while also testing out your skill with some of the concepts you've learned over the semester. I value poetry, the extreme and unexpected movement, the ambush. But these are not wanton gestures that seek to disguise a lack of thought or attention. The trick is to guide the grace of intellect into conversation with the bountiful chaos of exploration.

\section{Goal:}

1) Develop a multi-page, non-linear essay using Scalar's unique abilities to configure the flow and paths of information. This project will incorporate concepts from your previous essays, reconstructed and summarized for this new media platform.

2) It will include new ideas and examples harvested from the vast digital field (online articles, websites, videos, audio). 
3) The project will cross-references with your classmate's projects to enhance, expand and re-route your own ideas.

\section{Method:}

1) create an account on Scalar

2) get added to the class "book" project

3) create your own "path"

4) write out your paper in Word, then copy and paste it into Text Edit or a similar Rich Text format.

5) begin uploading/pasting content to the 5 or more pages you will create in your "path"

6) meet with the members of your thematically organized node to discuss intersections, gaps, and confluences

7) sketch out a node "map" that links all projects together

8) rewrite sections as needed to transition between pages and paths

9) consider co-writing with other members of the node to produce overviews, summaries, definition pages, etc.

10) decide on key tags and tag pages appropriately

11) explore the entire project

12) link your path with others across the class

The project must consist of:

5 distinct pages and approximately 1500 words of written content total.

3 links to classmates' projects. Of these links, you must analyze and discuss at least one, incorporating it further into your own work.

3 links to outside academic or journalistic sources - either print, audio, or video.

You may include as many outside links as you choose beyond this limit, but be circumspect, balancing content w/ analysis. I expect you to both use old content (reading notes, essays) and to generate new content. The old work will need to be summarized/rewritten to fit the new media, and you will need to write new sections that elaborate on ideas or analyze content you are introducing.

\section{Citations:}

For your citations, which you MUST include, you can provide a conventional citation at the bottom of the relevant page, just like you would do for a paper. I recommend including these wherever necessary to be on the safe side. But you can/should also 
include hotlinks to the Google book version if available. Some journal articles are behind digital gates unless you go through Duke Library, which all readers won't have (out in the real world), so you MUST include a written citation there, like for some of Larkin's pieces, for example. Books should be easier to create hotlinks for, like Games of Empire or Guattari's Chaosmosis.

\section{Tagging:}

This is a very simple but highly useful organizing and search function. For each page/post you have the option to put in tags. Type in key words separated by a comma. You can always go back and add more tags. Then, when you are looking through everyone's uploads, you can search for terms you may be interested in- "Guattari," for example, or "Blair Witch Project" or "drone". Be sure to tag - this will ensure your content becomes more visible to others and in turn you'll be able to find relevant information among your classmates. In the end all the blogs will be digitally stitched together through a series of tags and links.

\section{Grading:}

I will be looking first of all to see if you complete the various requirements of the assignment as detailed below. Second, I want to see how you introduce new examples and material and analyze that material critically using the theories and arguments we've studied. Third, I will be evaluating how well you incorporate your classmates' work into your own. Finally, I'll be looking at the structure of your project-how do the different parts link together and produce a coherent but provocative assemblage of ideas organized around a focused argument.

\section{Recommendations:}

I like to sketch a little map with all my content visible and then draw lines connecting the different bits of info. For example, a theory page might outline key concepts. It should have some outside links, maybe a video illustrating, say, Guattari or Deleuze's idea of the rhizome. Then figure out how the other pages might incorporate links, references, and or tags that lead a reader back to the relevant sections in that page. Sometimes a video might get linked on several pages. Integrate links into the body of the text using the hyperlink function.

As usual, consult w/ me if you need help thinking through the organization of your material.

In reference to how much of your previous writing you can use, here's what I wrote to a student in a previous class in response to this question:

Partially the purpose of this project is for you to "give" or share your ideas w/ others, esp your classmates, so they can build and connect to your thinking. So I want you to use as much of your previous writing as makes sense. You can copy entire passages/paragraphs or pages. Just remember you will likely need to edit or rewrite some sections to make sense. But think of Lev Manovich's ideas about modularity and remixability. Remix yourself! You're not stealing, you're re-using! Instead of your previous writing being 
"dead" or without a future, it suddenly finds new life in a different form. This is a kind of radical practice that teaches us something about our lives, not just about academic work.

$\mathrm{Ok}$, that does it for now. Send me more questions as you think of them. I know this project is asking a lot of you-technically and academically-so hit me up for clarifications. I'll also continue to scan your work in progress as you put it up and if something doesn't look right, I'll let you know. I also suggest you get friends to use your site, or other classmates. User feedback is CRITICAL, and srsly, working out kinks and bugs in your blog will help me evaluate you better. OK?

\section{Timeline:}

\section{The project will be produced over the course of 9 days.}

1) Choose your focus. Pick an object of analysis-it can be exploring theory, like Guattari, or it can be a site or machine like drones, Facebook, NSA internet surveillance, or Turkish Anonymous hackers.

2) On Day 1 upload a rough outline to your Sakai Dropbox. You should map out 5 separate, stand-alone pages that relate to one another thematically. You may use portions of previous writing, either essays or reading notes or both. You will probably need to revise and certainly you will write more around/incorporating this text. Basically, think of this as a loosely structured $5+$ page essay with each page as a section covering a specific area of thinking/analysis that connects or unfolds to the next section.

3) Begin writing over the break! The more you have done, the easier it is to edit and for your classmates and myself to help you organize and refine your work.

4) In class on Day 2, I'll map out the thematic clusters from your different foci. We will collectively organize into nodes-working groups of 3-4 students. You will coordinate with your classmates to meet and work together to map out the connections between your individual projects.

5) By Day 6 you should have a good portion of your writing done.

6) Continue to meet with your node members on Day $6 / 7$

7) On Day 8: we'll meet to have a pizza party and look at the final projects as they near completion. We'll discuss links between nodes and the experience you all had working on the project.

8) By midnight of Day 9 your individual and node projects must be totally written, edited, and linked to your classmates' across our class' Scalar network.

\section{Remember:}

This experiment has several goals: an opportunity to think actively with your classmates and remix/resurrect your previous writing, a way to enact, formally, living knowledge in a collectively produced and critiqued digital landscape, and a problem in building 
coherent ideas into related sets or strata of knowledge while discovering shared facets or connections.

This project should not be a stressful, confusing thing. I want you to take risks while building upon your previous work. You will be able to embed media like videos and audio clips and then analyze them. You will be able to support your arguments using your classmates' writing! This is huge: if you need help explaining an idea, you don't have to just do it alone-you can draw on the smart, expert work of your peers to assist you.

We will be using Scalar to do all this. Necessarily, this will require some technical training, but it's pretty straightforward. I will be available to meet with nodes throughout the week to help organize, edit, and create links.

\section{All readings are suspended for the rest of the semester. I want you to exclusively focus on this project.}

Lastly, do not fear the grade. Assume you are getting an A on this project as long as you push yourself and your peers. I expect you to be equally invested in your own project, writing, and analysis and in the node aspect of building connections and relationships.

Pay attention to the timeline-we don't have much time to do this. I'm here to support you and you can also turn to your peers for help. I want this to be as fun as possible while also intellectually invigorating.

So do lots of writing over break, even if it's not so refined or great. Just get ideas out there. Mess around on the internet to find some things to think or write about. Build on your strengths and interests.

Have a good break and I'll see you on Tuesday morning!

\section{References}

Deleuze, G., \& Guattari, F. (1987). A thousand plateaus: Capitalism and schizophrenia. Minneapolis: University of Minnesota Press.

Guattari, F. (1995). Chaosmosis: An ethico-aesthetic paradigm. Bloomington, IN: University of Indiana Press. 